\title{
Assessment of trapped powder removal and inspection strategies for powder bed fusion techniques
}

\author{
Luke W. Hunter $^{1} \cdot$ David Brackett $^{2} \cdot$ Nick Brierley $^{2} \cdot$ Jian Yang ${ }^{2} \cdot$ Moataz M. Attallah $^{1}$
}

Received: 10 August 2019 / Accepted: 9 January 2020 / Published online: 22 January 2020

(C) The Author(s) 2020

\begin{abstract}
The issue of trapped powder within a part made using powder bed fusion additive manufacturing (AM) is one of the 'dirty secrets' of AM, yet it has not received significant attention by the research community. Trapped powders limit the application of AM for complex geometries, including heat exchangers and dies with conformal cooling channels. Being able to detect and remove trapped powder from the build is a necessary step to avoid downstream processing and performance challenges. In this work, 'powder challenge geometries' with complex internal features were fabricated via laser powder bed fusion (L-PBF) and electron beam selective melting (EBSM) and were used to assess the effectiveness of several powder removal and inspection methods. Hand-held ultrasonic polishing was explored as a powder removal technique and was shown to effectively clear extremely elongated channels that grit-blasting (the current industry standard) cannot clear. X-ray computed tomography (XCT) and weighing were used to inspect and quantitatively assess the effectiveness of powder removal techniques on the challenge geometries. Using the lesser known 'vacuum boiling' powder removal process and the more common ultrasonic bathing process, trapped L-PBF powder was easily removed from the deep channels. Conversely, trapped EBSM powder was difficult to remove using ultrasonic polishing as the powder was sintered inside the channels. It was shown that the powder recovered by the ultrasonic polishing process had size distributions, surface chemistry, morphology and porosity similar to the virgin powder. It is suggested, on these bases, that the recovered powder could likely be recycled without detrimental effects on the process operation.
\end{abstract}

Keywords Additive manufacturing $\cdot$ Post-processing $\cdot$ Inspection $\cdot$ Micro-CT

\section{Introduction}

Powder bed fusion (PBF) is a class of additive manufacturing (AM) processes, which uses a bed of fine powders, where thin layers of powders $(20-100 \mu \mathrm{m})$ are spread and selectively melted in a layer by layer fashion to build a component. Trapped powder is the term given to any remaining, unwanted, semi-sintered or loose powder left inside the component cavities after build completion, either due to geometrical constraints, pre-sintering or partial consolidation of powders. This powder is problematic during post-processing as it can fully sinter during hot isostatic pressing and heat treatment or can

Moataz M. Attallah

m.m.attallah@bham.ac.uk

1 School of Metallurgy and Materials, University of Birmingham, B15 2TT, Edgbaston, UK

2 The Manufacturing Technology Centre, Antsy Park, Coventry CV7 9JU, UK block the cooling channels of a turbine blade or an injection moulding die. In the blade example, if trapped powder went undetected, the blade would not cool effectively during service and could melt inside the engine [1], leading to a catastrophic engine failure. Also of importance in biomedical implants, any loose powder trapped inside implant pores could be discharged into the body, causing inflammation or blocking blood vessels [2]. It is therefore vital to investigate inspection and removal methods for trapped powders in AM structures. The purpose of this work is to critically assess the literature on trapped powder removal and non-destructive inspection techniques, and to investigate their utility using geometrical challenges.

\subsection{Trapped powder removal}

Powder removal is typically a two-stage process: stage 1 involves mechanically breaking up and dislodging the powder and stage 2 involves destroying or transporting the loosened powder out of the cavity using a fluid [3]. Several stage 1 techniques have been previously investigated including: grit- 
blasting [4-7], dry-ice blasting [8] and structurally induced removal [9]. A number of stage 2 techniques have also been investigated such as corrosive baths [7, 10], electrochemical and plasma polishing [11, 12], ultrasonic baths [10] and 'vacuum boiling' [13]. Grit-blasting has become the industry standard and subsequently the most researched. Adam and Zimmer [4] showed that grit-blasting can successfully clear trapped powders from straight, through-thickness L-PBF channels with diameter length ratios less than 1:200. However, data from Drescher et al. [5] and Vayre et al. [6] appear to show a proportional relationship that grit-blasting becomes progressively more difficult at smaller diameters, whereas polishing does not. Hasib et al. [7] investigated the use of chemical etching methods for sintered powder removal and showed that gritblasting compacted the powder's surface, making the trapped powder impermeable to acid infiltration and removal. This problem may also occur during electrochemical and plasma polishing techniques which also rely on fluid permeation. Hence, grit-blasting is of limited use for small channels.

Ultrasonic cleaning is widely used as a stage 2 technique [3] and is effective at removing trapped material from polyjet acrylic test pieces [10]. However, sonicating may damage small features due to the explosive collapse of cavitation bubbles. Additionally it may not be effective on large geometries due to the inverse-square energy intensity drop with distance from the sonotrode [14]. Another option may be 'vacuum boiling' which utilises a sealed, depressurised container with the object to be cleaned submerged in water [13]. Air is evacuated from the container and the boiling point of water reduces below room temperature [15], causing bubbles of water vapour to nucleate and grow (preferentially on solid surfaces). Assuming a stagnant and homogenous liquid, pressure should be uniform according to Pascal's law [16, p., 76] and bubble nucleation should not decrease with container size (as long as depths are not excessive). The technique has been demonstrated to effectively remove trapped powder from binder jetted alumina cavities smaller than $150 \mu \mathrm{m}$ [13]. In this paper, we investigate its application to metal parts.

\subsection{Trapped powder inspection}

Inspection of trapped powder in prior investigations was fairly simple due to the simple test piece geometries. Successful techniques demonstrated for inspecting test geometries have included 'ruler-drop' [4-7, 10] — where a ruled object is used to measure the depth of the cavity and this depth relative to the designed depth is used as a measure of remaining powder, microscopy $[7,10]$ and shadowgraphs $[5,17]$. However, some AM parts have complex internal geometries and may require nonline-of-sight inspection techniques. This has led to the widespread use of X-ray computed tomography (XCT) for trapped powder inspection. XCT of AM components is occasionally required for structural integrity checks, with powder inspection being an additional result, but in the general case, the technique is time-consuming and expensive and adds significant costs to each part [18]. An effective solution to this was given by Verhaagen et al. [10] who detailed a 'powder challenge device'. This idea stems from the medical industry, where batch inspection of many instruments with complex internal geometries is substituted by a single object with an internal geometry of greater complexity. If inspection reveals this object to be clean, then the entire batch is assumed clean. Verhaagen et al. proposed a challenge device consisting of straight, blind channels $15 \mathrm{~mm}$ deep, with diameters ranging from $0.25-5 \mathrm{~mm}$. These features were chosen based on their prior tests of channels with geometries that were challenging to remove powder from.

\subsection{Trapped powder reuse}

It is often noted that AM processes do not generate a large amount of material waste and therefore have lower buy-to-fly ratios than conventional metal processes (such as casting) [19]. As well as needing to remove trapped powder from a part functionality point of view, it is economical to reuse powder. Hence, it is important to assess whether powder removal processes preserve the powder's properties. Tang et al. [20] studied the effect of repeated instances of grit-blasting, sieving and electron beam selective melting (EBSM) build cycles on particle size distribution (PSD), morphology and chemical composition of Ti-6Al-4V powder. Results showed that the PSD narrows with increasing reuse and the particles appear rougher with reduced sphericity [21]. It also appeared that after 21 reuses, the oxygen concentration increased by 58\% [20]. Another important powder feature was the presence of internal porosity, which has been shown to directly result in detrimental porosity in as-built L-PBF [22] and EBSM [23] parts.

To the authors' knowledge, there is no prior investigation that directly compares the performance of powder removal and inspection techniques with subsequent morphological and rheological analyses of the recovered powder to assess the possibility of its reuse. In this work, powder challenge devices have been designed with complex internal geometries (mimicking those seen in real AM components) and have been subjected to several powder removal techniques. Inspection of the challenge devices has been carried out to reveal if their designs are suitable and removal techniques successful. Finally, powder recovered from the stage 1 removal technique was characterised to assess its suitability for reuse.

\section{Methodology}

\subsection{Challenge device design and fabrication}

The powder challenge devices with complex geometry (Fig. 1) were designed using SolidWorks, incorporating 


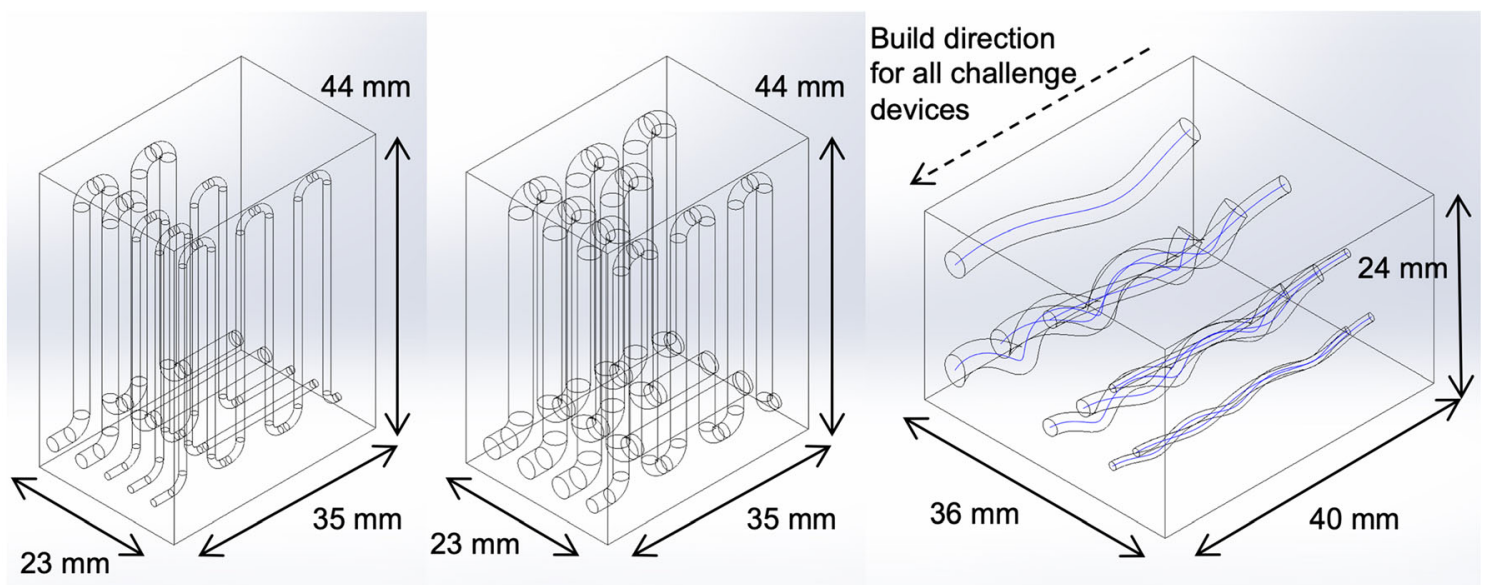

Fig. 1 CAD drawings of the complex powder challenge devices. U-bend channels are $34.5-\mathrm{mm}$ tall. The smallest spacing between channels is $3 \mathrm{~mm}$

internal features that were deemed challenging to remove powder from based on [4-7, 10] and opinions from engineers at The Manufacturing Technology Centre (MTC), Coventry, UK. The device consists of many helix and U-bend channels of different diameter and number of rotations and bends (see Table 1). Concern over the size of the device for full XCT penetration and mass for weighing accuracy led to its segmentation into three pieces. To better assess different techniques' effectiveness against industry standard grit-blasting, a simpler device that had features similar to those in other work $[5,6]$ was designed and fabricated (in the same way as the complex device) - channel dimensions are also given in Table 1.

Three sets of each complex device were fabricated using an M2 Cusing L-PBF system (Concept Laser, Germany) equipped with a Nd:YAG laser with a wavelength of $1075 \mathrm{~nm}$, constant beam spot size of $70 \mu \mathrm{m}$, laser power of $150 \mathrm{~W}$, scan speed of $1750 \mathrm{~mm} / \mathrm{s}$, hatch spacing of $75 \mu \mathrm{m}$ and layer thickness of $30 \mu \mathrm{m}$ using a 'chessboard' scan pattern within an argon atmosphere. Another two sets were fabricated using an A2XX EBSM system (Arcam, Sweden), the process parameters for which are proprietary, but are tailored to generate fully dense Ti-6Al-4V structures. The nominal characteristics of the pre-alloyed powder used in both systems are given in Table 2. After fabrication, each device was lightly grit-blasted and mechanically shaken $(10 \min$ in $\mathrm{x}, \mathrm{y}$ and $\mathrm{z}$ directions) during a cleaning stage to remove any loose powder from their surfaces and internal features (standard industry practice) to allow for assessment of any remaining trapped powder. It was later revealed that this process led to different starting amounts of trapped powder in each complex device. Hence, wherever possible, distributions and percentages were used instead of raw values to compare the effectiveness.

\subsection{Powder removal and inspection}

Removal and inspection techniques were down selected using a Pugh matrix (a tool to qualitatively rank options against criteria [27]). Suitable criteria, such as cost and speed, were
Table 1 Dimensions of channels investigated in this work (in $\mathrm{mm}$ )

\begin{tabular}{|c|c|c|c|c|c|c|c|}
\hline \multirow{2}{*}{\multicolumn{2}{|c|}{$\frac{\text { Simple devices }}{\text { Straight channels }}$}} & \multicolumn{6}{|c|}{ Complex devices } \\
\hline & & \multicolumn{3}{|c|}{ U-bend channels } & \multicolumn{3}{|c|}{ Helix channels } \\
\hline Diameter & $\begin{array}{l}\text { End-to-end } \\
\text { displacement }\end{array}$ & Diameter & $\begin{array}{l}\text { Number } \\
\text { of } \\
\text { U-bends }\end{array}$ & $\begin{array}{l}\text { End-to-end } \\
\text { displacement }\end{array}$ & Diameter & $\begin{array}{l}\text { Number } \\
\text { of } \\
\text { rotations }\end{array}$ & $\begin{array}{l}\text { End-to-end } \\
\text { displacement }\end{array}$ \\
\hline 1 & 35 & 1 & 1 & 32 & 1 & 1 & 35 \\
\hline 2 & 35 & 1 & 3 & 32 & 1 & 2 & 35 \\
\hline \multirow[t]{7}{*}{3} & 35 & 1 & 5 & 32 & 1 & 3 & 35 \\
\hline & & 2 & 1 & 32 & 2 & 1 & 35 \\
\hline & & 2 & 3 & 32 & 2 & 2 & 35 \\
\hline & & 2 & 5 & 32 & 2 & 3 & 35 \\
\hline & & 3 & 1 & 32 & 3 & 1 & 35 \\
\hline & & 3 & 3 & 32 & 3 & 2 & 35 \\
\hline & & 3 & 5 & 32 & 3 & 3 & 35 \\
\hline
\end{tabular}


Table 2 Specification of the L-PBF and EBSM powder used

\begin{tabular}{lll}
\hline $\begin{array}{l}\text { Production method } \\
\text { Size range/ } \mu \mathrm{m}\end{array}$ & $\begin{array}{l}\text { L-PBF } \\
\text { Gas atomised } \\
20-63\end{array}$ & $\begin{array}{l}\text { EBSM } \\
\text { Plasma atomised } \\
45-105\end{array}$ \\
\hline Al wt\% & 5.9 & 6 \\
V wt\% & 3.9 & 4 \\
Fe wt\% & 0.19 & 0.1 \\
O wt\% & 0.12 & 0.15 \\
C wt\% & 0.01 & 0.03 \\
N wt $\%$ & 0.01 & 0.01 \\
H wt\% & 0.004 & 0.003 \\
Ti wt $\%$ & Balance & Balance \\
Supplier & TLS Technik & Arcam \\
\hline
\end{tabular}

determined from prior reviews of powder removal and inspection techniques [24-26]. From these criteria, the following powder removal techniques were chosen: stage 1, a handheld ultrasonic polisher with flexible tooltip; stage 2, ultrasonic bathing and vacuum boiling. These three techniques were used to design three channel clearing regimes: ultrasonic polishing; ultrasonic polishing with ultrasonic bathing; and ultrasonic polishing with vacuum boiling. XCT and weighing were determined to be the most suitable inspection techniques.

Each complex device was weighed against a reference using a mass balance $( \pm 0.001 \mathrm{~g})$, then scanned using a 225 XCT machine (Nikon Metrology, UK). Centred on the gauge length, 4 devices were scanned at a time (2 stacks of 2). Scanning was performed with an accelerating voltage of $195 \mathrm{kV}$ and a tube current of $123 \mu \mathrm{A}$ with a $2-\mathrm{mm}$ copper plate filter. The 22502 -D projections acquired were reconstructed using a filtered back projection algorithm to produce 3 -D data with a voxel size of $46 \mu \mathrm{m}$. The reconstructions were viewed and processed using VGStudio MAX 2.2.6 (Volume Graphics, Germany). After this, a Sheenus Neo hand-held polisher (Kemet International, UK) with steel wire tooltips of 0.6-2.6 mm diameter was used to remove trapped powder from each of the device's channels. Any powder removed from both the simple and complex devices was recovered for characterisation. The first set of complex devices were then shaken, weighed and XCTed again. The second set of complex devices were placed in an ultrasonic bath for $20 \mathrm{~min}$, removed and then dried in a vacuum furnace (programme $105^{\circ} \mathrm{C}$ for $6 \mathrm{~h}$ ). The third set of complex devices were submerged in $55{ }^{\circ} \mathrm{C}$ water inside a sealed desiccator (Fig. 2) which was subsequently depressurised to $\sim 100$ mbar for $20 \mathrm{~min}$ (bubbling was observed to occur for the full $20 \mathrm{~min}$ ), removed and then dried in the same way. After drying, both sets of complex devices were XCTed and weighed again in the same way.

For quantitative comparison on the effectiveness of the trapped powder removal techniques, both inspection techniques had to measure the same quantity accurately. The most accurate weighing scale available was used (calibrated to $\pm 1 \mathrm{mg}$ ). However, an individual Ti-6Al-4V powder particle of $45-\mu \mathrm{m}$ diameter was roughly $10 \mathrm{ng}$. Therefore, the weighing scale could only measure upwards of 100,000 particles. At a typical packing factor of 0.56 [28], the minimum volume change of powder reliably detectable was roughly $1 \mathrm{~mm}^{3}$, which could be enough to block a channel $1 \mathrm{~mm}$ in diameter. This is the sensitivity limit of the weighing scale technique.

It is now easy to compare this sensitivity to the theoretical limit of an XCT system using a voxel size of $46 \mu \mathrm{m}$, which would reliably detect volumes of powder an order of magnitude smaller than the weighing scales used here could. However, the powder's density was too similar to the part's and the voxel size was too large to distinguish individual particles to allow separation based on image contrast alone during post-processing. Since it was not possible to automatically measure volumes of powder removed here, a more involved method was used (Fig. 3). The 3-D XCT reconstruction of the part was sectioned in the plane of the internal channels. The chosen 2-D sections bisected the channels widths and regions of interest (ROIs) were digitally painted onto the images where trapped powder was observed. The software, Fiji (image analysis freeware, courtesy of NIH [29]), was then used to measure the area of the ROIs (calibrated with the image scale bar). Upper and lower bounds of aspect ratio for each ROI were estimated. Using the measured areas and aspect ratio upper and lower bounds, lengths and heights of the trapped powder regions powder were calculated and used in Eq. 1 to finally calculate upper and lower bounds of trapped powder volume.

volume $=\frac{1}{2} l r^{2}\left(\left(2 \cos ^{-1}\left(\frac{r-f}{r}\right)\right)-\sin \left(2 \cos ^{-1}\left(\frac{r-f}{r}\right)\right)\right)$

Eq. 1 Equation showing relationship between volume, projected height (f), radius ( $\mathrm{r}$ ) and length (l) of a cylinder

Once an upper and lower bound of volume of trapped powder before and after powder removal experiments was obtained, an overall upper and lower bound for volume of powder removed could be calculated. These values were then multiplied by the theoretical density of Ti-6Al-4V: $4.42 \mathrm{~g} \mathrm{~cm}^{-3}[30$, p., 372] and a powder packing factor of 0.56. A simple calculation of this method's sensitivity, based on Eq. 1 and assumed human measurement error, yields a minimum detectable volume change on the order of $1 \mathrm{~mm}^{3}$. This is comparable to the sensitivity limit of the weighing scales. Additionally, this XCT method is limited because it can only measure channel cavities that are solids of revolution about the Cartesian plane. Therefore, it was not possible to quantify trapped powder 
Fig. 2 Vacuum boiling apparatus

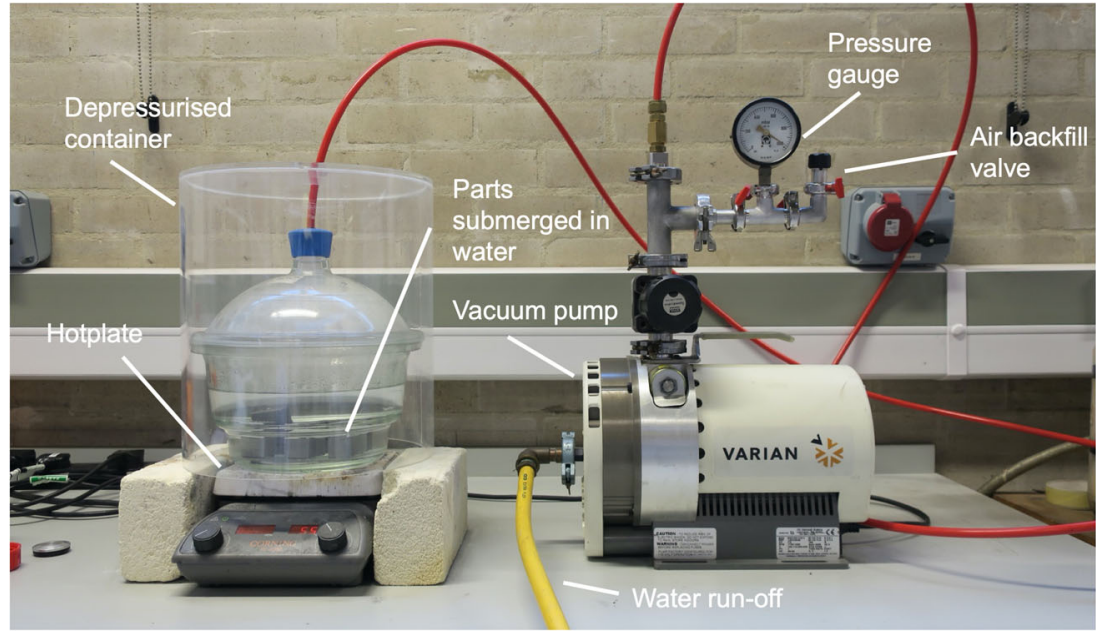

removal from helix channels using XCT. However, comparing $\mathrm{XCT}$ data points to equivalent weighing data points (obtained during experiments) showed both techniques' data correlated strongly when measuring changes but the absolute magnitudes differed by a factor of two.

After the challenge devices had been inspected, they were sectioned along the $\mathrm{X}-\mathrm{Z}$ plane then mounted, ground and finally polished using a $0.05-\mu \mathrm{m}$ silica colloidal suspension. The porosity of specimens was analysed using tessellated micrographs taken using an Axioskop2 optical microscope equipped with AxioVison image capture software (Zeiss, Germany) and quantified as an area fraction using Fiji.

\subsection{Powder characterisation}

Any powder removed during the ultrasonic polishing stage was collected for characterisation, mixed (as if being reused), and segmented into three samples of equal mass. Particle size distributions of each sample were determined using the laser diffraction method of particles using a Mastersizer 3000 in accordance with [31]. Thirty measurements from each sample were collected and averaged. Chemical composition and qualitative morphology were investigated using a TM3000 table-top SEM (Hitachi, Japan) with energy-dispersive X-ray spectroscopy (EDS). To measure internal porosity, powder was
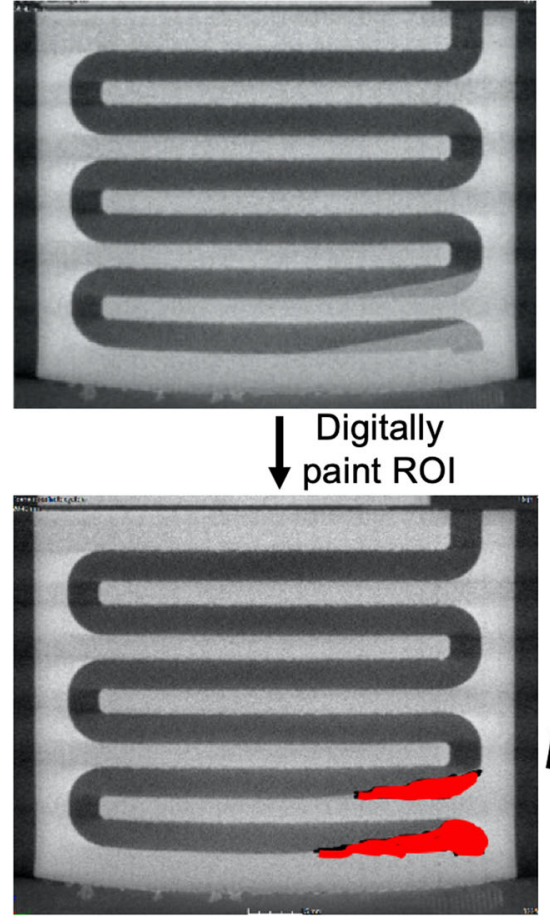

paint ROI
Fig. 3 Diagram illustrating process of determining mass of trapped powder removed via XCT calculate possible length of $\mathrm{ROI}$ for each given fill height using idealized geometry shown below
Calculate aspect ratios from these lengths and fill heights $\left(\mathrm{mm}^{2}\right)$ of painted ROI with Fiji calibrated with scale bar

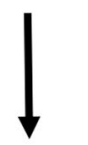

From ROI area and possible fill heights ( $\mathrm{min}$ is 0 and max is $2 r$ ),

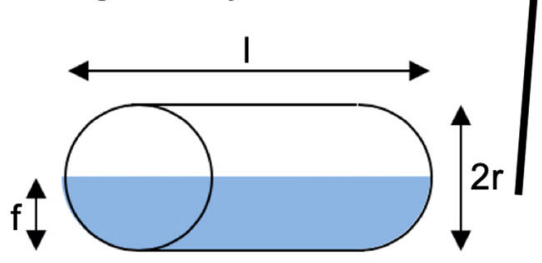
and limit to reasonable values

Calculate volumes of powder in channel from: equation 1 , possible lengths, and fill heights; then plot volume of powder vs aspect ratio range

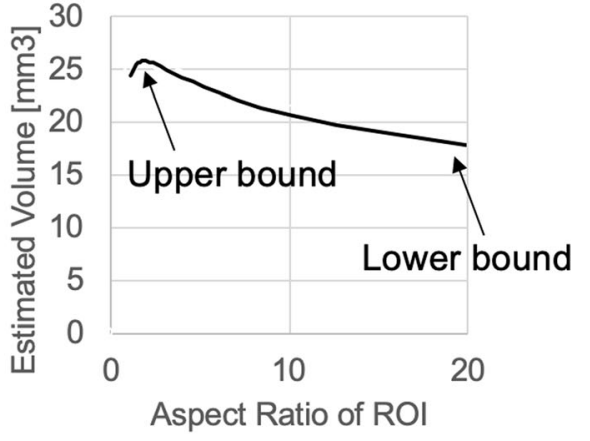




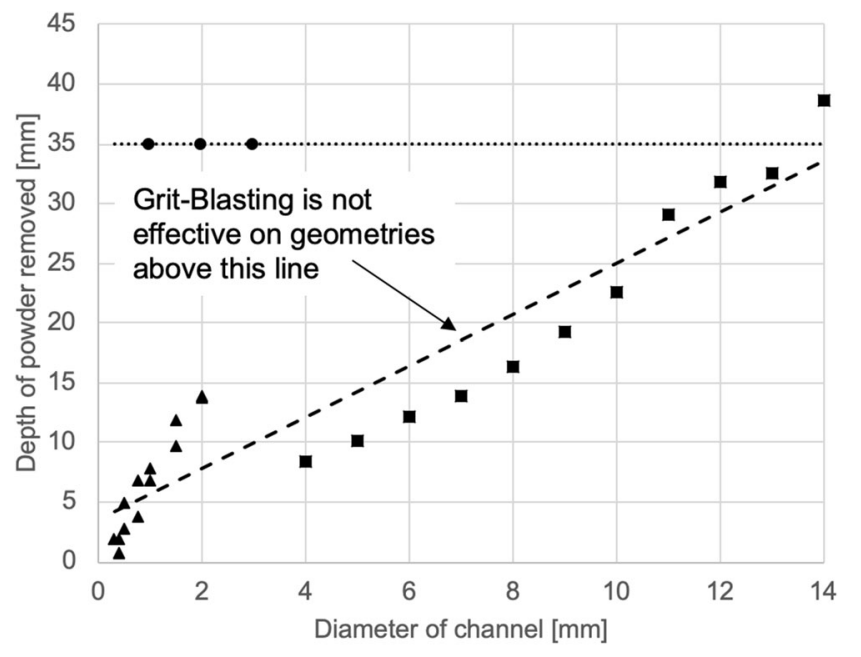

- Hand-Held Ultrasonic Polishing [This work]

- Grit Blasting [5]

- Grit Blasting [6]

........ Linear Trendline of Hand-Held Ultrasonic Polishing data

- - - Linear Trendline of Grit-Blasting data

Fig. 4 Graph of previous investigations on grit-blasting of EBSM channels and this work for comparison (the dashed lines are only to illustrate the trend)

mounted in conductive Bakelite, ground and finally polished using a $0.05-\mu \mathrm{m}$ silica colloidal suspension to reveal the cross-section of the particles. Fiji was then used to measure the area fraction of pores relative to the total cross-sectional area of the particles.

\section{Results and discussion}

\subsection{Powder removal and inspection}

\subsubsection{Performance of powder removal techniques on simple devices}

Trapped powder removal results of hand-held ultrasonic polishing on the simple challenge devices are shown in Fig. 4 and is compared with prior work. When a tooltip of marginally smaller diameter was used to sonicate the trapped powder in each channel, it rapidly (under $10 \mathrm{~s}$ ) and successfully cleared the full length. No remaining trapped powder could be observed by eye. This observation was corroborated by inserting piece of wire $35 \mathrm{~mm}$ into the channel fully (a 'ruler-drop' test). Ultrasonic polishing appears superior to grit-blasting for removing trapped powder from thin, straight channels.

\subsubsection{Performance of powder removal techniques on complex devices}

Before-and-after example XCT images of each powder removal technique are shown in Fig. 5. They qualitatively illustrate trapped powder locations and corroborate quantitative powder removal data in Fig. 6. Most of the trapped powder in the L-PBF devices was removed after both ultrasonic polishing with ultrasonic bathing and ultrasonic polishing with vacuum boiling. The EBSM devices retained much of the original trapped powder after every powder removal

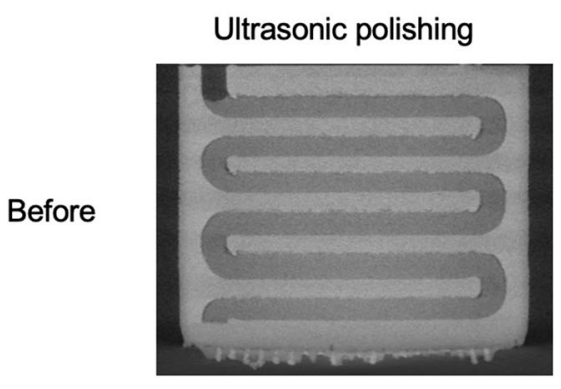

After

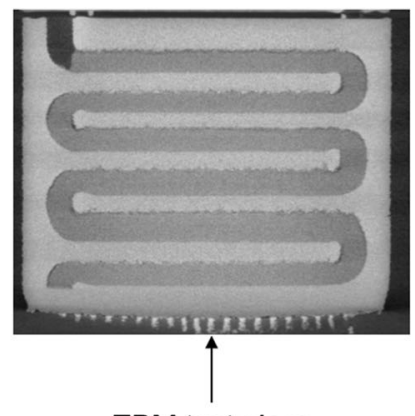

EBM test piece

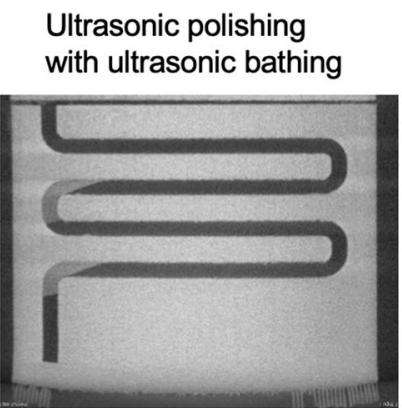

Utrasonic polishing with vacuum boiling
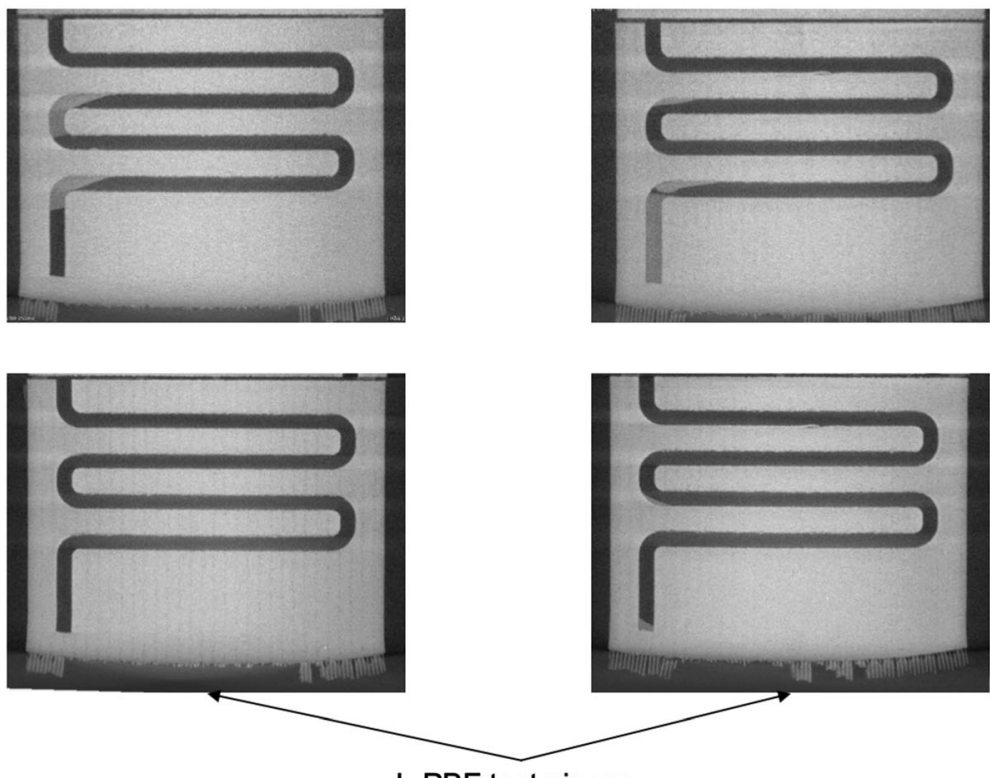

L-PBF test pieces

Fig. 5 XCT images of some selected features of different complex challenge devices 
a

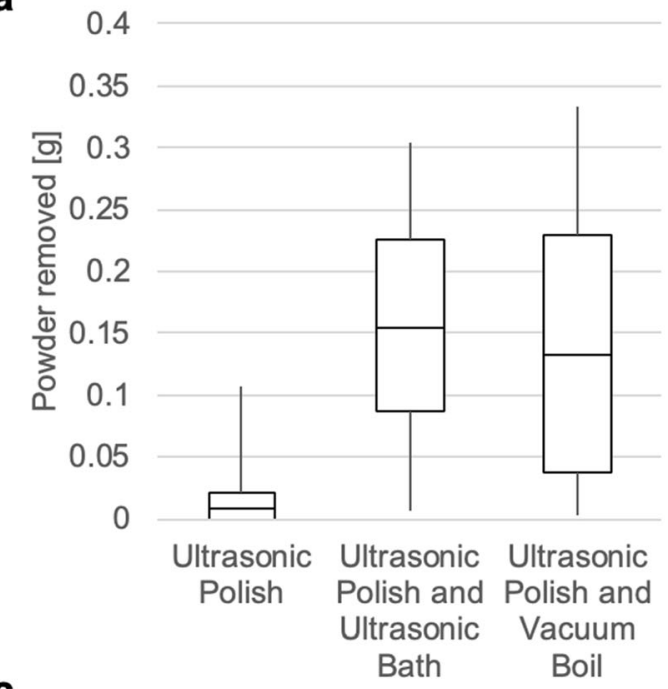

c

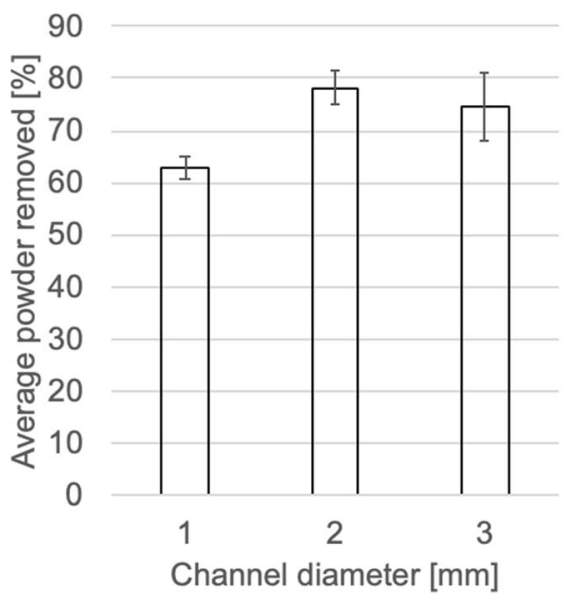

Fig. 6 Boxplots showing a comparison of powder removed by each removal technique across all complex devices; $\mathbf{b}$ comparison of powder removed from complex devices manufactured via L-PBF and EBSM, the interquartile range of each dataset is denoted by the grey box outline, the 1 st quartile and 3rd quartile correspond to the bottom and top of each box respectively, the black lines inside the boxes correspond to the median of each dataset, the whiskers denote the maximum and minimum recorded

technique. This was likely because EBSM pre-sintered the powder. As exemplified in the image of the EBSM U-bend challenge device, the polisher removed little powder from the complex devices. It was originally hoped that the thin wire tooltips would bend inside the channels. However, after forcing around a U-bend, the wire quickly fractured at its fastening to the sonotrode, presumably because of fatigue. Shallower bends, like those in the helix devices, did allow tooltip infiltration and powder removal. Shallow bend tooltip infiltration was the main reason for the powder removal from the complex EBSM devices.

Figure 6a compares the performance of all the powder removal techniques. Available data from both measuring techniques: weighing, XCT; both fabrication processes: L-PBF, EBSM; and each complex device was included. In total,

\section{b}

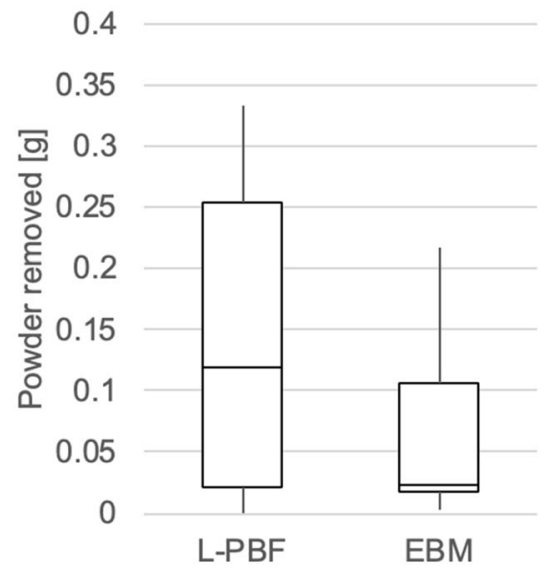

d

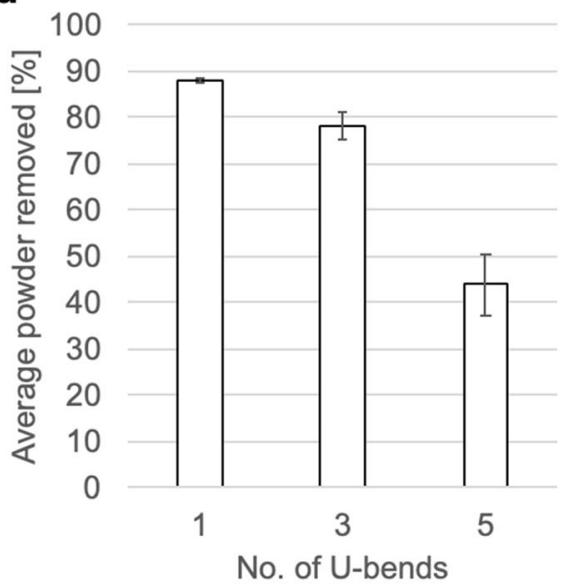

values; bar charts where the top and bottom of each error bar indicate the average of the upper and lower bound values determined using the procedure outlined in the 'Powder removal and inspection' section; c average powder removed from each U-bend device based on channel diameter; $\mathbf{d}$ average powder removed from each U-bend device based on the number of bends

twenty data points were used. The distributions show that the combined stage 1 with stage 2 techniques performed better than stage 1 alone. It appears that, because of the tighter distribution around larger values, ultrasonic polishing with ultrasonic bathing was more effective than ultrasonic polishing with vacuum boiling. However, boiling was conducted using prototype apparatus without any optimisation, while bathing was conducted using commercial equipment. It is possible that with refinement, vacuum boiling's performance could be significantly improved. Statistical analysis was not performed as it was not expected to assist valid comparison of this experiment's small dataset.

Figure $6 \mathrm{~b}$ compares the relative difficulty of removing trapped powder from challenge devices fabricated by L-PBF and EBSM. The distributions suggest that L-PBF devices 
Table 3 Advantages and disadvantages of powder removal techniques identified in these experiments

\begin{tabular}{|c|c|c|c|}
\hline & Ultrasonic polishing & Ultrasonic bathing & Vacuum boiling \\
\hline Advantages & $\begin{array}{l}\text { - Effective on small diameter, straight } \\
\text { channels } \\
\text { - Cheap } \\
\text { - Fast }\end{array}$ & $\begin{array}{l}\text { - Widely available apparatus } \\
\text { - Effective on small diameter, straight channels } \\
\text { and tortuous channels }\end{array}$ & $\begin{array}{l}\text { - Potentially less damaging than ultrasonic } \\
\text { bathing } \\
\text { - Effective on small diameter, straight channels } \\
\text { and tortuous channels }\end{array}$ \\
\hline Disadvantages & $\begin{array}{l}\text { - Requires more elaborate tooling for } \\
\text { tortuous channels }\end{array}$ & $\begin{array}{l}\text { - Potential to damage small features } \\
\text { - Requires part to be submerged in liquid }\end{array}$ & $\begin{array}{l}\text { - Complicated set-up } \\
\text { - Requires part to be submerged in liquid }\end{array}$ \\
\hline
\end{tabular}

were easier to remove powder from than those made via EBSM. As already discussed, the EBSM U-bend devices were the most challenging to remove powder from as the tooltip of the ultrasonic polisher could not bend around the channels and therefore could not make intimate contact with the powder. It seems that cohesion between the semi-sintered EBSM powder particles was greater than the force of vapour bubble growth during vacuum boiling, the force of cavitation bubble collapse during ultrasonic bathing, and the chemical dissolution of bonds by water [32]. It was, however, overcome by the cyclic impact from the ultrasonic polisher once contact was established. To ensure this occurs and is maintained in complex cavities, use of a shear thickening liquid that can harden upon ultrasonic oscillation and propagate these oscillations to the solid/liquid front could be developed. This idea has already been explored in $[33,34]$. The hypothesised reasons for the EBSM trapped powder's cohesion are discussed in the 'Powder characterisation' section.

Figure $6 \mathrm{c}$ and $\mathrm{d}$ shows the mean percentage of powder removed per feature across both L-PBF removal techniques. Figure $6 \mathrm{c}$ and $\mathrm{d}$ uses percentage change as the measure of powder removal because only XCT data is used. Using XCT allowed calculations of percentage change of powder removal from the initial amount of powder present (from Fig. 6c, it can be seen that this is typically $60-80 \%$ ), weighing only allowed calculations of percentage change from the initial entire mass of the device (values were typically $0.01 \%$ ). This technique also somewhat accounts for the differences in initial starting amounts of powder. Figure $6 \mathrm{c}$ shows that that the larger the channel diameter, the greater the amount of powder removed, and Fig. $6 \mathrm{~d}$ shows that the more U-bends in the channel the lesser the amount of powder removed. The greater the channel complexity, the less powder is removed. These observations are expected and can be explained by larger unobstructed volumes allowing free movement of powder out from the channels.

Overall, for devices of complex internal geometry, ultrasonic polishing is not recommended unless more elaborate tooltips that can maintain intimate contact with trapped powder are available. Ultrasonic bathing and vacuum boiling both removed similar amounts of powder across all complex devices. Complex EBSM devices were much more difficult to remove powder from than complex L-PBF devices. Increasing channel tortuosity and slenderness makes powder removal more difficult. A summary of the advantages and disadvantages of each powder removal technique identified in this work is detailed in Table 3.

\subsubsection{Performance of powder inspection methods on complex devices}

Figure 6 shows relative agreement between the mass of powder removed obtained via XCT and weighing across different

Table 4 Advantages and disadvantages of powder inspection techniques identified in these experiments

\begin{tabular}{|c|c|c|}
\hline & The XCT methodology used in this experiment & Weighing \\
\hline Advantages & $\begin{array}{l}\text { - Can locate trapped powder } \\
\text { - Quantification of remaining trapped powder possible } \\
\text { - Inspection of individual features are possible rather than the } \\
\text { entire test piece giving crucial information about } \\
\text { problematic designs }\end{array}$ & $\begin{array}{l}\text { - Quick } \\
\text { - Easy } \\
\text { - Widely available apparatus }\end{array}$ \\
\hline Disadvantages & $\begin{array}{l}\text { - Expensive by comparison to weighing } \\
\text { - Extremely time-consuming data processing } \\
\text { - Quantitatively far less accurate } \\
\text { - Cannot quantify on certain geometries (such as helix) }\end{array}$ & $\begin{array}{l}\text { - Cannot examine individual features, only the whole test piece } \\
\text { - Requires careful cleaning of the test piece before weighing (so dirt is } \\
\text { not recorded as powder being removed) } \\
\text { - No way of knowing when all powder has been removed as asperity } \\
\text { sizes (surface roughness) are the same order of magnitude mass as } \\
\text { the powder particles/agglomerations ( } \sim 10 \mathrm{ng} \text { ), any change in } \\
\text { surface roughness could be attributed to more trapped powder and } \\
\text { therefore even comparing to other test pieces known to be } \\
\text { powder-free would be too inaccurate }\end{array}$ \\
\hline
\end{tabular}


complex devices and their features. This result suggests that the quantification method for XCT described in the 'Powder removal and inspection' section is a reasonable approximation. It also suggests that for certain simpler geometries, 2-D radiography (a simpler and less expensive technique) might be suitable for inspecting trapped powder, and quantifying the amount.

However, both have serious shortcomings identified during the course of this work, detailed in Table 4. In summary, despite its disadvantages, XCT of a 'powder challenge device' is viewed as the best inspection technique simply because it can locate trapped powder. This provides invaluable detail and context to AM part design, the powder removal techniques' effectiveness and could be used to inform predictive models [35] of problematic designs.

\subsection{Powder characterisation}

\subsubsection{Particle size}

Initially it was thought that frictional heating of the sonicated tooltip and powder might weld the particles. However, no size change appears to have taken place in the L-PBF sample; the PSD of both virgin and recovered powder appears almost identical (Fig. 7) and values of $d_{10}, d_{50}$ and $d_{90}$ values were alike (Table 5). This is not the case with the EBSM powder. From Fig. 7, it is clear that the size distribution of the recovered powder is broader, especially towards higher magnitudes, as evidenced by the higher $\mathrm{d}_{90}$ value of recovered versus virgin powder (Table 5).

Micrographs of the recovered EBSM powder (Fig. 8) show groups of powder particles less than $200 \mathrm{~nm}$ apart. It is highly likely that the particles are in intimate contact-agglomerates. Agglomerates like these can cause many problems in PBF processes including increased part surface roughness [36], impede powder spreading [37] and higher porosity in the bed
Table 5 Particle size distribution metrics of L-PBF and EBSM powder samples. Uncertainties were calculated as machine measurement errors based the assumption that each datum was only measurable to $\pm 0.05 \mu \mathrm{m}$

\begin{tabular}{lrrrrr}
\hline & \multicolumn{2}{l}{ L-PBF } & & \multicolumn{2}{l}{ EBSM } \\
\cline { 2 - 3 } \cline { 5 - 6 } \cline { 5 - 6 } & \multicolumn{1}{l}{ Virgin } & Recovered & \multicolumn{1}{l}{ Virgin } & \multicolumn{1}{l}{ Recovered } \\
\hline $\mathrm{d}_{10}(\mu \mathrm{m})$ & $32 \pm 0.05$ & $30.5 \pm 0.05$ & & $55 \pm 0.05$ & $49.1 \pm 0.05$ \\
$\mathrm{~d}_{50}(\mu \mathrm{m})$ & $44.4 \pm 0.05$ & $43.1 \pm 0.05$ & & $76.6 \pm 0.05$ & $76.6 \pm 0.05$ \\
$\mathrm{~d}_{90}(\mu \mathrm{m})$ & $61.5 \pm 0.05$ & $60.6 \pm 0.05$ & & $106.7 \pm 0.05$ & $121 \pm 0.05$ \\
\hline
\end{tabular}

[38]. Agglomerates were not observed in the virgin powder and therefore must have formed during part fabrication or powder removal stages. The possible causes of agglomeration include thermally assisted diffusion sintering of powder as a normal side effect of the EBSM process, frictional heating from the ultrasonic probe causing particle fusion welding, spontaneous contact sintering caused by Van der Waal's forces when particles are extremely close [32, pp., 197-9]. Figure 8 shows the particles have not changed shape, ruling out welding. Determining whether contact sintering or diffusion sintering is responsible for the agglomerations is more difficult. Using Eq. 2 [32] and values of $\gamma_{\mathrm{LV}}$ and $\theta$ for water $\left(70.5 \mathrm{~mJ} \mathrm{~m}^{-2}\right.$ at $20{ }^{\circ} \mathrm{C}$ [39]) and water wetting the surface oxides of Ti6Al4V $\left(88^{\circ}\right.$ at $\left.20^{\circ} \mathrm{C}[40]\right), W_{\text {dry }}$ must be at least $79 \mathrm{~mJ} \mathrm{~m}^{-2}$ ('at least' because of the reducing effects of surface roughness and contamination).

$W_{\text {immersed }}=W_{\mathrm{dry}}-\gamma_{L V}\left(\cos \theta_{1}+\cos \theta_{2}\right)$

Eq. 2 Work (energy) required to separate two solid surfaces that are adhered together immersed in a liquid, $W_{\text {immersed }}$ is the work of adhesion between two solid surfaces in a liquid which can be calculated using the Young-Dupré equation where $W_{\text {immersed }}=\gamma_{\mathrm{LV}}(1+\cos \theta)[41], W_{\text {dry }}$ is the work of adhesion
Fig. 7 Particle size distributions of $\mathbf{a}$ L-PBF and $\mathbf{b}$ EBSM powder samples a

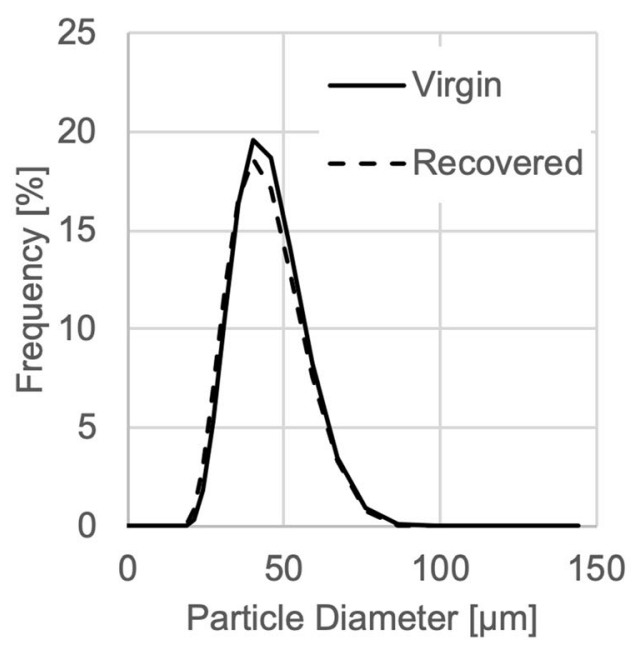

b

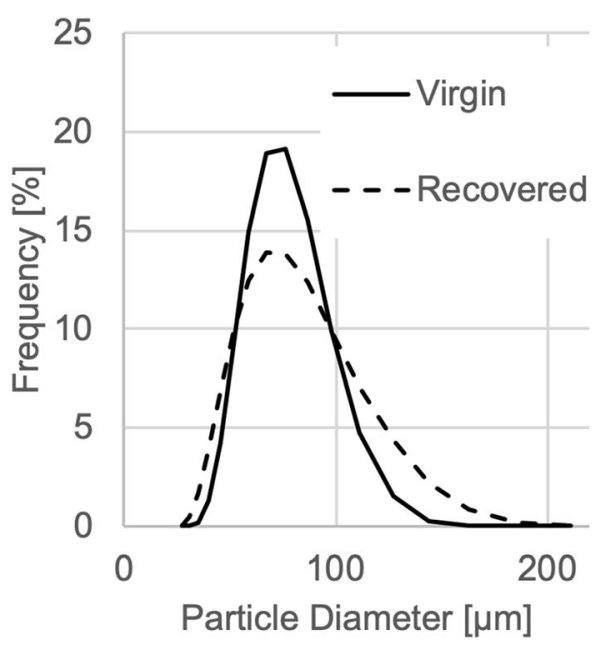




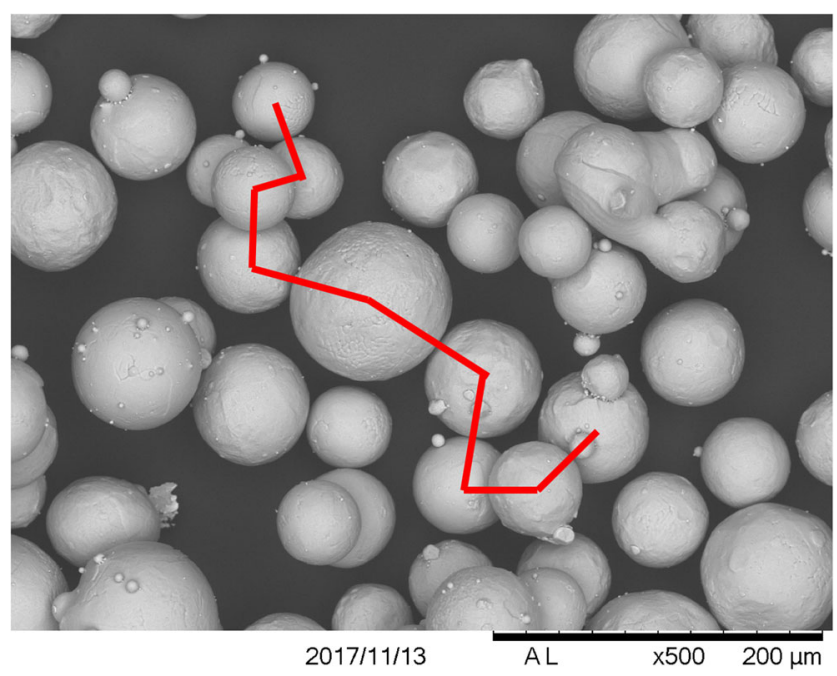

Fig. 8 SEM micrograph of EBSM powder recovered using the hand-held ultrasonic polisher with a tree-like agglomerate highlighted

between two solid surfaces in a vapour, $\gamma_{\mathrm{LV}}$ is the surface tension of the liquid/vapour interface, $\theta_{1}$ and $\theta_{2}$ are the contact angles between the liquid and the two solid surfaces being wetted

This value corresponds to typical work of adhesion values caused by Van der Waal's bonds [], which are responsible for contact sintering bridge strengths. Hence, it is difficult to rule out this mechanism. However, it does not matter for the purposes of reusing the powder, whether contact sintering or diffusion sintering has occurred (as long as sphericity remains unchanged) as Tang et al. [20] has shown these agglomerations are broken apart during grit-blasting. Figure $7 \mathrm{~b}$ also shows slight broadening towards smaller sized particles in the recovered EBSM powder. There are many possible explanations for this including wear between the sonotrode and powder eroding the particles, partially melted powder from the walls of the challenge device breaking loose, virgin powder satellites braking off. However, this is also not an issue as particle sieving will take place before reuse and most particles outside the specified size ranges will be removed [43].

\subsubsection{Porosity}

Table 6 shows the average internal porosities of L-PBF and EBSM virgin and recovered samples. The overall higher porosity in the L-PBF virgin powder is a result of the processing route; L-PBF powder was gas atomised (GA) whereas the

Table 6 Internal porosity of different powder samples, uncertainties were calculated based on one standard deviation of all measured values from the mean values shown

\begin{tabular}{lllll}
\hline L-PBF & & & EBSM & \\
\cline { 1 - 2 } \cline { 5 - 5 } Virgin & Recovered & & Virgin & Recovered \\
\hline $0.062 \pm 0.018 \%$ & $0.091 \pm 0.033 \%$ & & $0.013 \pm 0.004 \%$ & $0.025 \pm 0.006 \%$ \\
\hline
\end{tabular}

EBSM powder was plasma atomised (PA). Internal powder porosity is typically a result of frozen-in voids or gas pockets [44], GA utilises hot gas jets whereas PA utilises far hotter plasma jets that result in slower cooling. This keeps the powder molten for longer and allows more time for gas to escape and surface tension to equilibrate a solid sphere [45]. Porosity was higher in recovered samples, nearly twice the virgin porosity in the case of EBSM. This could potentially mean that twice as much porosity would be present in fabricated parts. However, gas porosity of the challenge devices was revealed to be extremely low and it is therefore unlikely that a twofold increase would be an issue. Also, recovered powder is usually blended with some amount of virgin powder before fabrication and therefore the actual porosity of the powder bed would be lower than in the recovered powder.

\subsubsection{Morphology and chemistry}

Recovered and virgin L-PBF and EBSM powder appeared very similar under SEM (Fig. 9). EBSM samples appeared fairly spherical and apart from the agglomeration discussed, no other notable differences were seen.

L-PBF powder samples displayed poorly spherical particles, many with satellite attachments, elongations and broken sections. Since these defects were present in both samples, it can be concluded that they are the result of the GA process and not because of damage sustained during recovery. These features of GA powder have been noted before $[22,23]$. The recovered sample also appeared to have fewer highly spherical particles compared with the virgin sample. Sphericity of powder relates to its flowability during layer raking [46]. However, given the (qualitatively) few perfectly spherical particles seen in the virgin sample, it is unlikely that there would be a noticeable difference in virgin and recovered powder flowability. This lack of sphericity and the appearance of surface dents are evidence of particles hitting each other at high speeds and deforming, consistent with observations of gritblasted powder [20].

Surface chemistry by EDS analysis revealed no unexpected contaminants in the virgin or recovered EBSM powder. The LPBF powder appeared to contain silicon contaminations on its surface; however these were determined to be accidental contaminations from the polishing solution. Hence, it appears that LPBF and EBSM powder recovered by the hand-held ultrasonic polishing method was chemically alike to the virgin feedstock.

\section{Conclusions}

- Challenge devices with simple and complex internal geometry, produced via L-PBF and EBSM, with straight and helix blind channels down to $1 \mathrm{~mm}$ in diameter were successfully cleared of trapped powder using hand-held 
Fig. 9 SEM micrographs of LPBF (a-b) and EBSM (c-d) powder samples, $(\mathbf{a}, \mathbf{c})$ virgin powder, $(\mathbf{b}, \mathbf{d})$ recovered powder a

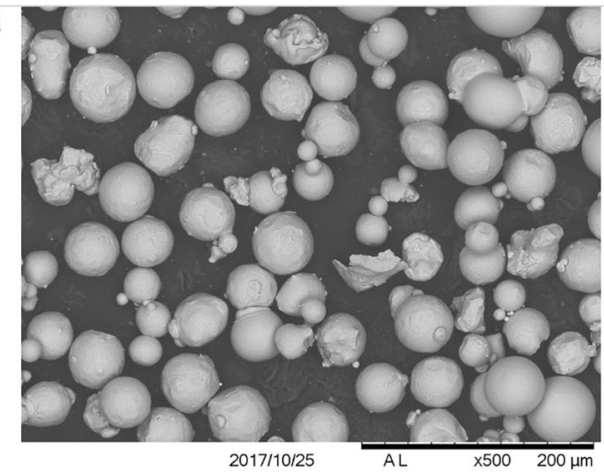

c

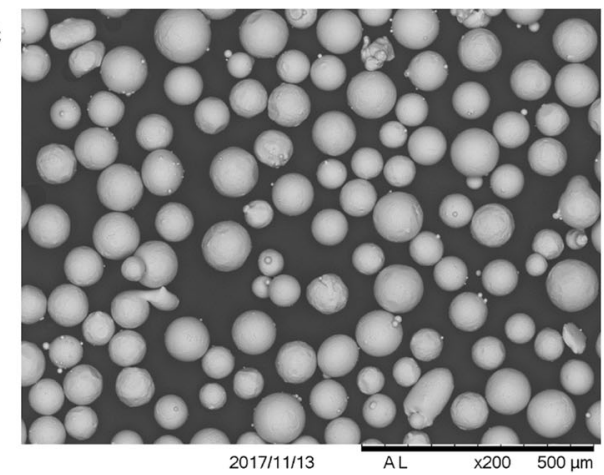

b

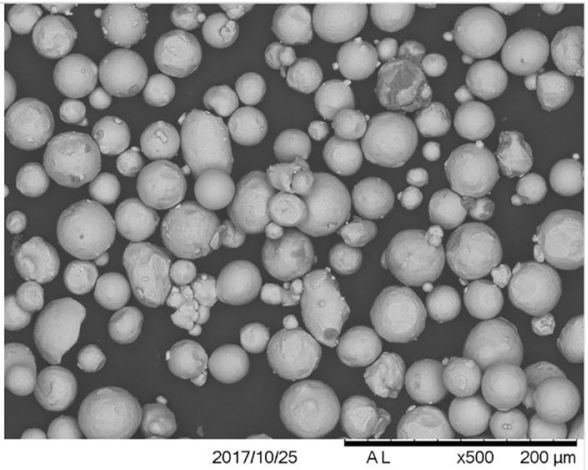

d

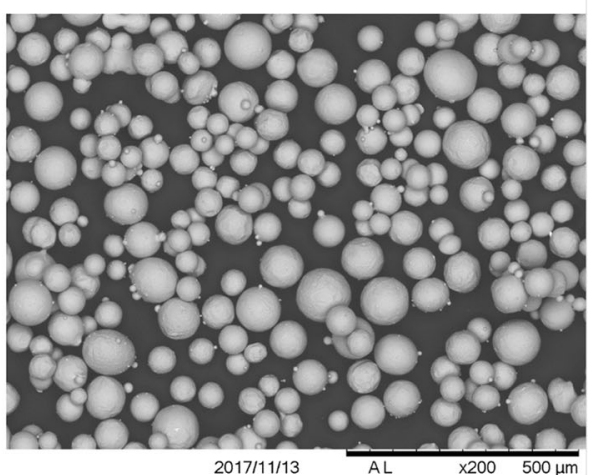

ultrasonic polishing. However, the technique was less successful at clearing channels with sharp U-bend turns. This was attributed to the tooltip's inability to make intimate contact with the powder inside.

- Two non-line-of-sight powder removal processes, ultrasonic bathing and vacuum boiling, demonstrated viability for clearing channels with sharp U-bends fabricated by LPBF. However, these techniques did not clear channels with sharp U-bends fabricated by EBSM, attributed to greater cohesion between these particles. Both techniques performed similarly overall, but it is expected that optimised vacuum boiling would perform best because it will not lose bubbling intensity with size.

- Two inspection techniques, XCT and weighing, were both able to quantify powder removal from different test pieces. $\mathrm{XCT}$ results of the L-PBF devices showed that rising complexity of internal geometry made powder removal more difficult. It is suggested that XCT is the more useful technique for quantifying powder removal, mostly because it permits locating powder and quantification of the amount left (not just the amount removed).

- Powder analysis (PSD, internal porosity, surface chemistry and morphology) was conducted on powder removed during hand-held ultrasonic polishing. PSDs, internal porosities and surface chemistries of both L-PBF and EBSM recovered powder were similar to the virgin feedstocks. However, recovered EBSM powder appeared slightly agglomerated in both PSD and SEM analysis and was most likely because of contact sintering or diffusion sintering. However, these agglomerates are easily dealt with. Trapped powder recovered from L-PBF and EBSM parts using hand-held ultrasonic polishing appears unaffected by the process and is likely reusable.

Acknowledgements The authors would like to thank Dr. Luke Carter, Amanda Field and Andy Bradshaw at the School of Metallurgy and Materials at the University of Birmingham for their assistance in sample building, material characterisation and prototyping the vacuum boiling rig. The co-authors would also like to thank Vukile Dumani, Faye Mills, Sean-Anthony Smith, Emmanuel Muzangaza, Ruaridh Mitchinson, Charlie McGuinness, Chris Turner and Annestacy Okioga from the National Centre for Additive Manufacturing at the Manufacturing Technology Centre (MTC), UK, for their assistance in experiment design, sample building and powder characterisation.

Open Access This article is licensed under a Creative Commons Attribution 4.0 International License, which permits use, sharing, adaptation, distribution and reproduction in any medium or format, as long as you give appropriate credit to the original author(s) and the source, provide a link to the Creative Commons licence, and indicate if changes were made. The images or other third party material in this article are included in the article's Creative Commons licence, unless indicated otherwise in a credit line to the material. If material is not included in the article's Creative Commons licence and your intended use is not permitted by statutory regulation or exceeds the permitted use, you will need to obtain permission directly from the copyright holder. To view a copy of this licence, visit http://creativecommons.org/licenses/by/4.0/. 


\section{References}

1. Clarke DR, Oechsner M, Padture NP (2012) Thermal-barrier coatings for more efficient gas-turbine engines. MRS Bull 37(10):891-898

2. Laing PG, Ferguson AB, Hodge ES (1967) Tissue reaction in rabbit muscle exposed to metallic implants. J Biomed Mater Res 1(1): 135-149

3. Sing SL, An J, Yeong WY, Wiria FE (2016) Laser and electronbeam powder-bed additive manufacturing of metallic implants: a review on processes, materials and designs. J Orthop Res 34(3): 369-385

4. Adam GAO, Zimmer D (2015) On design for additive manufacturing: evaluating geometrical limitations. Rapid Prototyp J 21(6):662-670

5. Drescher P, Reimann T, Seitz H (2014) Investigation of powder removal of net-structured titanium parts made from electron beam melting. Int J Rapid Manuf 4(2-4):81-89

6. Vayre B, Vignat F, Villeneuve F (2013) Identification on some design key parameters for additive manufacturing: application on electron beam melting. Procedia CIRP 7(Supplement C):264-269

7. Hasib H, Harrysson OLA, West HA (2015) Powder removal from Ti-6Al-4V cellular structures fabricated via electron beam melting. JOM 67(3):639-646

8. Uhlmann, E., et al. Flexible manufacturing with an additive process chain design, production and surface finish. in ASPE Spring topical meeting - Achieving precision tolerances in additive manufacturing (Proceedings). 2015. Raleigh, NC, USA

9. Merriam, E.G., J.E. Jones, and L.L. Howell, Design of 3D-printed titanium compliant mechanisms, in The 42nd Aerospace Mechanism Symposium. 2014: MD, USA. p. 169-174

10. Verhaagen B, Zanderink T, Fernandez Rivas D (2016) Ultrasonic cleaning of $3 \mathrm{D}$ printed objects and cleaning challenge devices. Appl Acoust 103(Part B):172-181

11. Almbrite. [cited 2018 12/9]; Available from: https:/www.eicgroup. co.uk/processes/almbrite

12. Hirtisation - Surface treatment Of 3D-printed metal parts. [cited 2018 12/9]; Available from: http:/hes.hirtenberger.com/en/ hirtisation/

13. Curodeau A, Sachs E, Caldarise S (2000) Design and fabrication of cast orthopedic implants with freeform surface textures from 3-D printed ceramic shell. J Biomed Mater Res 53(5):525-535

14. Leighton TG (2007) What is ultrasound? Prog Biophys Mol Biol 93(1):3-83

15. Saul A, Pruss A (1994) International equations for the pressure along the melting and along the sublimation curve of ordinary water substance. J Phys Chem Ref Data 23(3):515-527

16. White FM (2011) Fluid mechanics, 7th edn. McGraw-Hill, New York

17. Thomas, D., The development of design rules for selective laser melting. 2009, University of Cardiff

18. Thompson A, Maskery I, Leach RK (2016) X-ray computed tomography for additive manufacturing: a review. Meas Sci Technol 27(7):072001

19. Qiu C et al (2015) Fabrication of large Ti-6Al-4V structures by direct laser deposition. J Alloys Compd 629:351-361

20. Tang HP et al (2015) Effect of powder reuse times on additive manufacturing of Ti-6Al-4V by selective electron beam melting. JOM 67(3):555-563

21. Wadell H (1935) Volume, shape, and roundness of quartz particles. J Geol 43(3):250-280

22. Zhao $\mathrm{X}$ et al (2008) Study on microstructure and mechanical properties of laser rapid forming Inconel 718. Mater Sci Eng A 478(1):119-124

23. Sames, W., et al. Effect of process control and powder quality on Inconel 718 produced using electron beam melting. in 8th International Symposium on Superalloy 718 and Derivatives. 2014. John Wiley \& Sons, Inc.
24. Todorov E et al (2014) America Makes: National Additive Manufacturing Innovation Institute (NAMII) Project 1: Nondestructive evaluation (NDE) of complex metallic additive manufactured (AM) structures. Edison welding institute Inc, Columbus

25. Gordon ER et al (2016) A surface modification decision tree to influence design in additive manufacturing. In: Setchi $\mathrm{R}$ et al (eds) Sustainable design and manufacturing 2016. Springer International Publishing, Cham, pp 423-434

26. Seifi M et al (2017) Progress towards metal additive manufacturing standardization to support qualification and certification. JOM 69(3):439-455

27. Pugh, S. Concept selection: a method that works. in Proceedings International Conference on Engineering Design. 1981. Zürich: Heurista

28. Drescher P, Sarhan M, Seitz H (2016) An investigation of sintering parameters on titanium powder for electron beam melting processing optimization. Materials 9(12):974

29. Schindelin J et al (2012) Fiji: an open-source platform for biological-image analysis. Nat Methods 9:676

30. Polmear I et al (2017) Light alloys: from traditional alloys to nanocrystals, 5th edn. Butterworth-Heinemann, Oxford

31. ISO, 13320:2009 (2009) Laser diffraction methods. In: Particle size analysis. International Organization for Standardization, Geneva

32. Kendall K (2001) Molecular adhesion and its applications: the sticky universe, 1st edn. Kluwer Academic/Plenum Publishers, New York

33. Binghai, L., et al., Ultrasonic control shear thickening and polishing method and device. 2014, Zhejiang University of Technology: Hangzhou

34. Li M et al (2015) Shear-thickening polishing method. Int J Mach Tools Manuf 94(Supplement C):88-99

35. Brierley N, Bellon C, Lazaro Toralles B (2018) Optimized multishot imaging inspection design. Proc Math Phy Eng Sci 474(2216)

36. Spierings AB, Herres N, Levy G (2011) Influence of the particle size distribution on surface quality and mechanical properties in AM steel parts. Rapid Prototyp J 17(3):195-202

37. Krantz M, Zhang H, Zhu J (2009) Characterization of powder flow: static and dynamic testing. Powder Technol 194(3):239-245

38. Abd-Elghany K, Bourell DL (2012) Property evaluation of 304L stainless steel fabricated by selective laser melting. Rapid Prototyp J 18(5):420-428

39. Floriano MA, Angell CA (1990) Surface tension and molar surface free energy and entropy of water to -27.2 . degree. C. J Phys Chem 94(10):4199-4202

40. Hao L, Lawrence J, Li L (2005) Manipulation of the osteoblast response to a $\mathrm{Ti}-6 \mathrm{Al}-4 \mathrm{~V}$ titanium alloy using a high power diode laser. Appl Surf Sci 247(1):602-606

41. Schrader ME (1995) Young-dupre revisited. Langmuir 11(9):35853589

42. Kendall K (1988) Theoretical aspects of solid-solid adhesion. Sci Prog 72(2):155-171.

43. Slotwinski JA, Garboczi EJ, Stutzman PE, Ferraris CF, Watson SS, Peltz MA (2014) Characterization of metal powders used for additive manufacturing. J Res Natl Inst Stand Technol 119:460-493

44. Lawley A (1981) Atomization of specialty alloy powders. JOM 33(1):13-18

45. Entezarian M et al (1996) Plasma atomization: a new process for the production of fine, spherical powders. JOM 48(6):53-55

46. Strondl A et al (2015) Characterization and control of powder properties for additive manufacturing. JOM 67(3):549-554

Publisher's note Springer Nature remains neutral with regard to jurisdictional claims in published maps and institutional affiliations. 